\title{
1 The payoffs and tradeoffs of hygienic behavior: A large-scale 2 field study on a local population of honey bees.
}

3 Rya Seltzer ${ }^{1,2}$, Paz Kahanov ${ }^{1,3}$, Yosef Kamer $^{1}$, Amots Hetzroni ${ }^{1}$, Małgorzata

4 Bieńkowska ${ }^{4}$, Abraham Hefetz ${ }^{2,5}$, and Victoria Soroker ${ }^{1}$.

5

$6 \quad{ }^{1}$ Agricultural Research Organization, The Volcani Center, Rishon LeZion, Israel.

$7 \quad{ }^{2}$ School of Zoology, George S. Wise Faculty of Life Sciences, Tel Aviv University, Ramat Aviv, 8 Israel.

$9 \quad{ }^{3}$ The Mina and Everard Goodman Faculty of Life Sciences, Bar-Ilan University, Ramat Gan, Israel.

$10{ }^{4}$ Research Institute of Horticulture in Skierniewice, Apiculture Division, 24-100 Pulawy, Poland.

$11{ }^{5}$ Faculty of Marine Sciences, Ruppin Academic Center, Mikhmoret, Israel.

\section{Abstract}

13 Honey bees (Apis mellifera) are exposed to a variety of risk factors, but the ectoparasitic mite Varroa destructor and its associated viruses are considered to be

15 the most significant problem worldwide. It has been widely recognized that honey bee stocks resistant to the mites are an essential part of any sustainable long-term

17 management of Varroa. The aim of this study was to evaluate the efficacy of hygienic

18 behavior in a local population of honey bees in order to reduce Varroa infestation. A

19 bi-directional selection for high and low rates of hygienic behavior was carried out in

20 Israel using either queen artificially inseminated or naturally mated. Colonies were

21 screened for performance: population size, honey production, control of Varroa

22 infestation, and the level of hygienic behavior. Furthermore, we examined the costs

23 and benefits of selection using measurements of colony performance. Either way,

24 selected lines should be tested for trade-offs and benefits to ensure their productivity.

25 The selection process revealed that the trait is heritable. Maternal phenotype has a 26 significant effect on Varroa load, as colonies founded by hygienic daughter queens 27 showed a significantly lower parasite load. No major trade-offs were found between 
28 the rate of hygienic behavior, honey yield, and population size. Measuring the direct benefits of hygienic behavior through colony performance suggests that breeding for this trait makes bees more resistant to Varroa destructor. These results are promising for our successful local bee breeding programs in a Mediterranean climate.

Keywords: Apis mellifera/ breeding/ Varroa mite/ integrated pest management/ honey production

\section{Introduction}

The Western honey bee, Apis mellifera, is the main pollinator of agricultural crops globally (Delaplane and Mayer 2000; Klein et al. 2007; Dolezal et al. 2016). Over time, honey bee colonies have been selected for commercially important traits such as productivity (i.e., honey yields), colony strength, low swarming, and gentle

temperament. High colony losses in the last two decades have raised awareness of declining honey bee health and scientific efforts to determine and mitigate the causes of colony loss have been initiated (VanEngelsdorp and Meixner 2010; www.coloss.org). Although honey bees are exposed to a variety of risk factors, infestation by the ecto-parasitic mite, Varroa destructor, is considered to be the most significant health problem of A. mellifera worldwide (Genersch et al. 2010; Plettner et al. 2016). The Varroa mite is a highly specialized parasite on pupae and adult honey bees, feeding on their fat body (Ramsey et al. 2019). Beside its direct harm to the bees, it transmits about 18 different pathogenic viruses that are practically "injected" into the bees during mite's feeding. (Rosenkranz et al., 2010). These viruses weaken the bees, and cripple them, as in case of deformed wing virus (DWV) (Francis et al. 2013; Mondet et al. 2014; Zioni et al. 2011), as well as causing immunosuppression 
52 (Gregory et al. 2005; Ryabov et al. 2014; Zanni et al. 2017) and learning disabilities

53 (Rosenkranz et al., 2010). The devastating impact of these viruses is further

54 synergized by various agrochemicals (Simon-Delso et al. 2014; Steinhauer et al., 2018;

$55 \quad$ Yang and Cox-Foster 2005).

56 In order to fight this parasite, beekeepers have used a variety of mite control

57 methods, none of which proved fully satisfactory (Soroker et al., 2018). Moreover, the

58 extensive use of synthetic acaricides, especially in large beekeeping operations, may

59 leave residues that are toxic to bees and the consumers of hive products (Mullin et al.

60 2010). Furthermore, over time the mites develop resistance to all synthetic acaricides

61 available on the market, which renders its control critical (Sammataro et al. 2005;

62 Rosenkranz et al. 2010). For example in Israel, following years of successful use of

63 Fluvalinate and Coumaphos for mite control, their efficacy diminished and these

64 products are no longer in use (Afik, Ministry of Agriculture Extension Services,

65 personal communication). As an alternative, local Amitraz-based products are

66 currently used, but their efficacy against Varroa is declining (Zarchi, Ministry of

67 Agriculture Extension Services, personal communication). This situation necessitates

68 the development of a sustainable strategy for Varroa management that integrates a

69 number of approaches. Development of mite resistant honey bee stocks is widely

70 recognized as an essential part of any sustainable integrated Varroa management

71 (Dietemann et al. 2012; Sammataro and Avitabile 2011; Spivak and Gilliam 1998).

72 Social insects, including honey bees, display natural resistance mechanisms

73 against pests and pathogens, which involve both physiological and behavioral traits

74 (Evans and Spivak 2010). While Varroa infestation typically leads to colony failure

75 within one to two years (Rosenkranz et al. 2010), some colonies of Apis mellifera

76 from different parts of the world survive without being chemically treated (Büchler et 
77 al. 2010). Although the mechanisms leading to such resistance are not entirely clear, 78 behavioral traits are likely to play a role in these naturally resistant genotypes (Locke 2016). Several stocks of honey bees have been selectively bred for resistance to Varroa by phenotypic selection. The most prominent of these stocks in the USA are the Minnesota Hygienic Bees (Spivak and Euter 2001), the USDA-bred "Russian"

82 bees (Rinderer et al. 2001), and the Varroa-Sensitive Hygiene (VSH) stock that was 83 recently transitioned into the "Pol" line (Danka et al. 2016). Breeding efforts 84 elsewhere include, but are not limited to, breeding program in Canada (Guarna et al. 2015), selection programs in Germany (Gempe et al. 2016), France (Le Conte et al. 2011) as well as in other countries as recently reviewed by Le Conte et al. (2020). Most of the above programs relied on the improvement of brood-targeted hygienic behavior, the impact of which has been extensively investigated (Leclercq et al. 2017). It has been described as a complex behavior involving the detection, uncapping, and removal of damaged brood (Spivak and Gilliam 1998). In case of Varroa infestation, this behavior apparently interferes with the reproduction of the 92 mite (Arathi and Spivak 2001; Zakar et al. 2014). Between-generation, comparisons 93 of hygienic behavior performance demonstrated a significant genetic component for 94 this behavior (Scannapieco et al. 2017;). In addition, several studies reported that the 95 value of hygienic behavior heritability is as high as 0.65 (Boecking et al. 2000; Oxley 96 and Oldroyd 2010).

97 Research that compared performance of local and imported honey bees 98 indicated that breeding programs should rely on local populations, which are already 99 adapted to the immediate environment. Such local breeding efforts may prevent 100 diseases from spreading among populations while preserving global genetic diversity 101 (Büchler et al. 2014; Meixner et al. 2014; Uzunov et al. 2014). This is a strong 
102 argument against the exportation of queens from all over the world. Moreover,

103 practical success of a local breeding program must take into account possible

104 tradeoffs with other commercially desired traits, e.g., productivity, colony strength,

105 and gentle temperament. These may affect acceptance of selected resistant lines by

106 beekeepers (Uzunov et al. 2017; Leclercq et al. 2017). Trade-offs and benefits

107 between traits could be the result of pleiotropy, linkage between traits, or a genetic

108 correlation resulting from the selection on specific individuals which carry several

109 unrelated traits. While beekeepers often advocate importing superior stocks, a recent

110 multinational study showed that local stocks display significant advantages over

111 imported ones (Uzunov et al. 2014; Büchler et al. 2010; Niño and Cameron Jasper

112 2015, and Uzunov and Brascamp 2017).

113 More than 50 years ago in Israel, the local honey bee race A. mellifera syriaca

114 was actively displaced by A. mellifera ligustica that was also mixed over the years

115 with other races mainly, A. mellifera caucasica and Buckfast (Soroker et al. 2018).

116 However, we believe that over time the majority of the population had gradually

117 adapted to the local conditions of the region. This environment is characterized by hot

118 dry summers and cold rainy winters with a tendency towards drought years where the

119 colony loss occurs mostly in the summer. Varroa infestation further exacerbates

120 summer colony loss in Israel, where a 10-15\% loss was recorded in the last decade

121 due to extreme dry and hot weather conditions (V. Soroker, unpublished data). We

122 therefore assume that in the Mediterranean region, social immunity against the

123 Varroa mite expressed as hygienic behavior is most crucial when forage is scarce and

124 the population size is in decline.

125 The aim of this study was to screen the local honey bees in Israel for the level

126 of hygienic behavior and to evaluate its impact on Varroa infestation. While most 
127 breeding programs are carried out in Europe and North America (Doke et al. 2015),

128 our experimental program took place in Israel's Mediterranean climate. In order to

129 quantify the apicultural costs and the benefits of the trait as well as the commercial

130 applicability of selected lines under the conditions of obligatory regular chemical

131 treatment against Varroa, we conducted bidirectional selection for high and low

132 hygienic behavior.

\section{Materials \& Methods}

134 The study was conducted at the breeding apiary of the Volcani Center, Agricultural

135 Research Organization (ARO), Israel comprising local bee colonies that had been

136 previously selected for honey yield. The colonies had not received any queens from

137 an alien source since 2008. During 2012-2017, we performed a bi-directional

138 selection program based on queens reared from genetically unrelated colonies that

139 exhibited high or low hygienic phenotype. All selected colonies, regardless of their

140 hygienic performance, had honey production that was above average. Each year, six

141 to ten naturally-mated queens were selected based on their maternal lines (high and

142 low), according to the rate of hygienic behavior and honey production of their colony.

143 Ten to 15 colonies were established for each maternal line. In addition, in 2016 and

1442017 , artificially inseminated queens with sperm from 8-10 drones from either high or

145 low source colonies were used. The daughters of these queens were naturally mated

146 and used to establish new colonies that were assessed as described below.

147 The colonies and their subsequent generations in this project were distributed

148 within the apiary area and were assessed for honey yield, hygienic behavior, and

149 colony size. Colonies in which the queen superseded were excluded from analyses. In

150 total, this project included 437 colonies over the years, of which 112 were assessed 
151 for Varroa infestation (see Table 1). We built a data base containing the pedigree and

152 all the hive assessment data including their maternal phenotype (high or low hygienic

153 behavior) from 2012-2017. To prevent heavy loss, we treated all the colonies twice a

154 year against Varroa mite with Amitraz loaded strips (Galbitraz), in accordance with

155 guidelines from the Ministry of Agriculture Extension Service, first during July-

156 August and the second time during November-December.

157 Table 1: Summary of the types of colonies assessed throughout the study by year, according to 158 their maternal lines and mating techniques.

\begin{tabular}{|c|c|c|c|c|c|}
\hline Year & $\begin{array}{c}\text { Maternal } \\
\text { phenotype } \\
\text { (number of } \\
\text { maternal lines) }\end{array}$ & $\begin{array}{l}\text { Maternal } \\
\text { mating } \\
\text { techniques }\end{array}$ & $\begin{array}{l}\text { Nof colonies } \\
\text { tested for } \\
\text { honey yield } \\
\text { and hygienic } \\
\text { behaviour }\end{array}$ & $\begin{array}{c}\text { Seasonal } \\
\text { assessments } \\
\text { (number per } \\
\text { season) }\end{array}$ & $\begin{array}{c}\text { Varoa } \\
\text { assessments }\end{array}$ \\
\hline 2012 & $\begin{array}{l}\text { general population } \\
\qquad(14)\end{array}$ & $\begin{array}{l}\text { naturally- } \\
\text { mated }\end{array}$ & 69 & $\begin{array}{c}\text { beginning, middle, } \\
\text { and end } \\
\text { (once a season) }\end{array}$ & \\
\hline 2013 & $\begin{array}{c}\text { general population } \\
\text { (9) }\end{array}$ & $\begin{array}{l}\text { naturally- } \\
\text { mated }\end{array}$ & 50 & $\begin{array}{c}\text { beginning, middle, } \\
\text { and end } \\
\text { (once a season) }\end{array}$ & \\
\hline 2014 & $\begin{array}{c}\text { general } \\
\text { population(1), high } \\
\text { (4)and low(2) } \\
\text { hygienic behavior }\end{array}$ & $\begin{array}{l}\text { naturally- } \\
\text { mated }\end{array}$ & 73 & $\begin{array}{l}\text { beginning, middle, } \\
\text { and end } \\
\text { (three times in the } \\
\text { season) }\end{array}$ & $\begin{array}{l}\text { April until end } \\
\text { of July } \\
\text { (25 colonies) }\end{array}$ \\
\hline 2015 & $\begin{array}{c}\text { general population } \\
\text { (1), high (2)and low } \\
\text { (2) hygienic } \\
\text { behavior }\end{array}$ & $\begin{array}{l}\text { naturally- } \\
\text { mated }\end{array}$ & 98 & $\begin{array}{l}\text { beginning, and } \\
\text { middle } \\
\text { (once a season) }\end{array}$ & $\begin{array}{l}\text { April until end } \\
\text { of July } \\
\text { (16 colonies) }\end{array}$ \\
\hline 2016 & $\begin{array}{l}\text { high ( } 3 \text { ) and low ( } 2 \text { ) } \\
\text { hygienic behavior }\end{array}$ & $\begin{array}{l}\text { naturally- } \\
\text { mated } \\
\text { and } \\
\text { artificially } \\
\text { inseminated }\end{array}$ & 69 & $\begin{array}{c}\text { beginning, middle, } \\
\text { and end } \\
\text { (once a season) }\end{array}$ & $\begin{array}{l}\text { April until end } \\
\text { of July } \\
\text { (37 colonies) }\end{array}$ \\
\hline 2017 & $\begin{array}{l}\text { high (4) and low (1) } \\
\text { hygienic behavior }\end{array}$ & $\begin{array}{l}\text { naturally- } \\
\text { mated } \\
\text { and } \\
\text { artificially } \\
\text { inseminated }\end{array}$ & 73 & $\begin{array}{c}\text { beginning } \\
\text { (once a season) }\end{array}$ & $\begin{array}{l}\text { April until end } \\
\text { of July } \\
\text { (34 colonies) }\end{array}$ \\
\hline
\end{tabular}


160 Population size and hygienic behavior were evaluated three times a year according to

161 colony development and seasons. The early season occurs after winter Varroa

162 treatment. In our local conditions, this period is typified in by an exponential increase

163 in hive population and nectar flow, and takes place during the end of February until

164 mid-March. The second assessment is referred to as the mid-season, and it occurs just

165 after the spring honey harvest during May and June. The third assessment is referred

166 to as the late season, and it takes place following summer honey extraction and prior

167 to the second Varroa treatment during July and August. This period is characterized

168 by a population decline, which remains at a low level until after rain has fallen and

169 some flowering has occurred in October. In 2015, hygienic behavior was evaluated

170 three times in each season, in other words, nine times a year for each colony. This was

171 performed in order to determine the seasonal effect on hygienic behavior.

172 Population size was estimated by measuring the sealed brood area by counting the

173 number of decimeters containing pupae in each of the frames, according to Büchler et

174 al. (2013).

175 Hygienic behavior was measured using the "pin test" involving 100 cells containing

176 red eye pupae (Spivak and Gilliam 1998) as described in detail in Beebook (Büchler

177 et al. 2013). This entailed marking 100 cells and piercing them with an entomological

178 pin \#2. The proportion of uncapped and cleaned cells (brood removal) was calculated

179 by comparing pictures taken immediately after pinning, and 24 hours thereafter. The

180 proportions of uncapped and cleaned cells per colony was the basis for the bi-

181 directional selection for high and low hygienic behavior. Selection, however, was

182 based on uncapping behavior only, which was better distributed within the time frame

183 of the test. Consistently, extreme colonies were selected to establish the next

184 generation. Throughout, high hygienic colonies were defined if more than $75 \%$ 
185 uncapping occurred, and low hygienic colonies were defined if less than $45 \%$

186 uncapping occurred, of all pinned brood cells after 24 hours in three independent

187 tests.

188 Honey yield was assessed by weighing honey supers in the spring and summer, while

189 subtracting ten kilograms, the weight of an empty super.

190 Varroa infestation was measured weekly, during April and July for four out of the six

191 years of this experiment. It total, we measured infestation in 25 colonies in $2014 ; 16$

192 colonies in 2015; 37 colonies in 2016; and 34 colonies in 2017, using the method of

193 free-falling Varroa on a bottom tray (Dietemann et al. 2013). These colonies were all

194 located in one area of the apiary, and they represented similarly high and low hygienic

195 lines. Hives were placed on a $0.5 \times 0.5 \mathrm{~cm}$. screen board floor, and an oiled metal tray

196 was placed under it to record Varroa mites that die and/or fall to the bottom within 24

197 hours. For each colony, the number of mites caught on the trays after 24 hours served

198 as a measure of infestation level. The rate of increase in Varroa load over time was

199 estimated and the Varroa parasite load (measured as parasite $\mathrm{x}$ days) was calculated

200 based on the area under the curve, as a function of time from the first measurement. In

201 particular we calculated the value for each adjacent time points based on the formula

202 for trapeze area (S) calculation, when one of the trapeze bases is Varroa number at

203 time $t$ and the other base is its value at $t+1$, while the height of the trapeze is the time

204 between the measurements in days. We subsequently summed all the $\mathrm{S}$ values to

205 calculate the Varroa load over the entire period.

206 Statistical analysis was performed on seasonal and annual measurements of several

207 dependent variables for the same colony. These measurements were taken throughout

208 the year and analyzed in a compatible model. We analyzed how the selection process

209 affected hygienic behavior of the progeny using a three-way ANOVA with repeated 
210 measurements. For this, we took into consideration the following variables: maternal

211 mating type, maternal phenotype, assessment season, and all their interactions. The

212 variables were: seasonal measurements of hygienic behavior (proportions of

213 uncapping and cleaning) and colony size (sealed brood area). The fixed effects

214 analyzed were mating type, maternal phenotype, assessment season and all their

215 interactions. Random effects were year of testing and colony number nested within

216 mating type and maternal phenotype. Significant main effects were examined by the

217 Tukey HSD test. A two-way ANOVA model was applied for annual measurements of

218 spring, summer, annual honey yield, and Varroa infestation. The fixed effects that

219 were analyzed were maternal phenotype, year of testing and their interactions.

220 Pairwise association between hygienic behavior (uncapping and cleaning) and honey

221 yield were tested by Pearson Correlation. Significance was set at alpha=0.05. All

222 statistical tests were carried out using the JMP 14 Statistical Program (SAS, USA). 


\section{Results}

We tested the relationship between uncapping and cleaning behaviors. Figure

227 behavior: uncapping and cleaning (Pearson, $\mathrm{r}=0.87, p<0.0001)$. Still, the very high

228 rate of uncapping was not always followed by the high rate of cleaning.

229

230

231

232

233

234

235

236

237

238

239

240

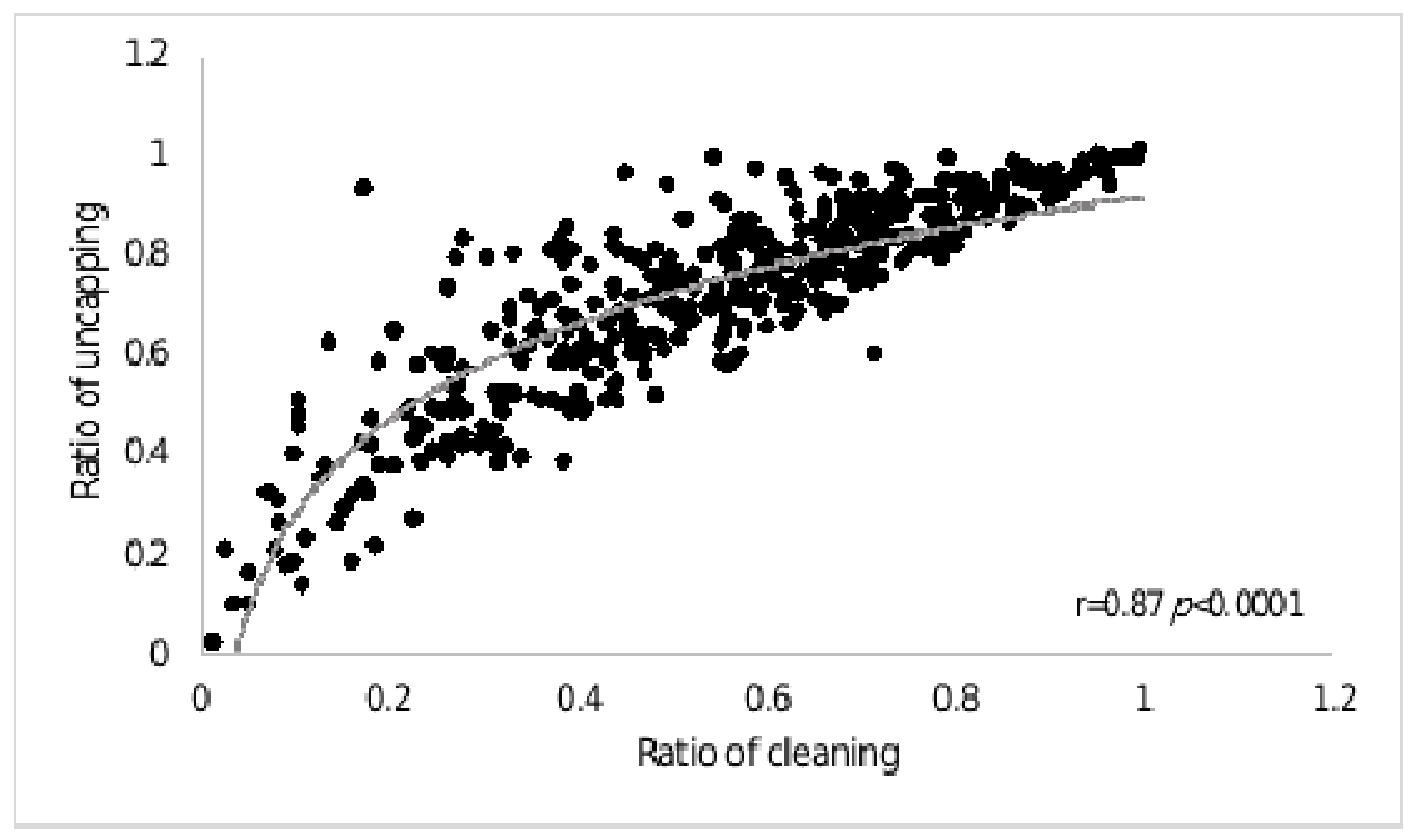

Fig. : The correlation between the rates of uncapping and cleaning behavior along the tested years. Each dot indicates a hygienic test, and $\mathrm{r}$ and $p$ are values of Pearson correlation.

Colony size as assessed by sealed-brood area was affected by the maternal phenotype $\left(\mathrm{F}_{(1,4)}=4.4, p=0.03\right)$. Progeny of low hygienic colonies had more sealed brood on average $(39.4 \pm 5.3 \mathrm{dm}( \pm \mathrm{SE}))$ than progeny of high hygienic colonies $(36.6 \pm$ $5.2 \mathrm{dm}( \pm \mathrm{SE})$ ). Maternal mating type did not have a significant effect on sealed-brood area $\left(\mathrm{F}_{(1,14)}=0.09, p=0.75\right)$.

However, as expected, there was a significant effect of seasonality on colony population size $\left(\mathrm{F}_{(2,662)}=559, p<0.0001\right.$, Fig. $)$. In early season the average sealed brood area was $46 \pm 3.6 \mathrm{dm}( \pm \mathrm{SE})$; in mid-season it was almost the same with an 
241 average of $47.2 \pm 3.7 \mathrm{dm}( \pm \mathrm{SE})$; in late season, however, it dropped significantly to 242 an average $24.5 \pm 3.7 \mathrm{dm}( \pm \mathrm{SE})$. Despite these seasonal fluctuations in population 243 size, we found no significant effect of seasonality on uncapping: $\left(\mathrm{F}_{(2,836)}=1, p=0.34\right.$, 244 Fig.2). Cleaning behavior was significantly higher in mid-season $(0.57 \pm 0.03( \pm \mathrm{SE}))$ 245 compared to late season $(0.52 \pm 0.03( \pm \mathrm{SE}))\left(\mathrm{F}_{(2,836)}=1.05, p=0.01\right.$, Fig. 2$)$.

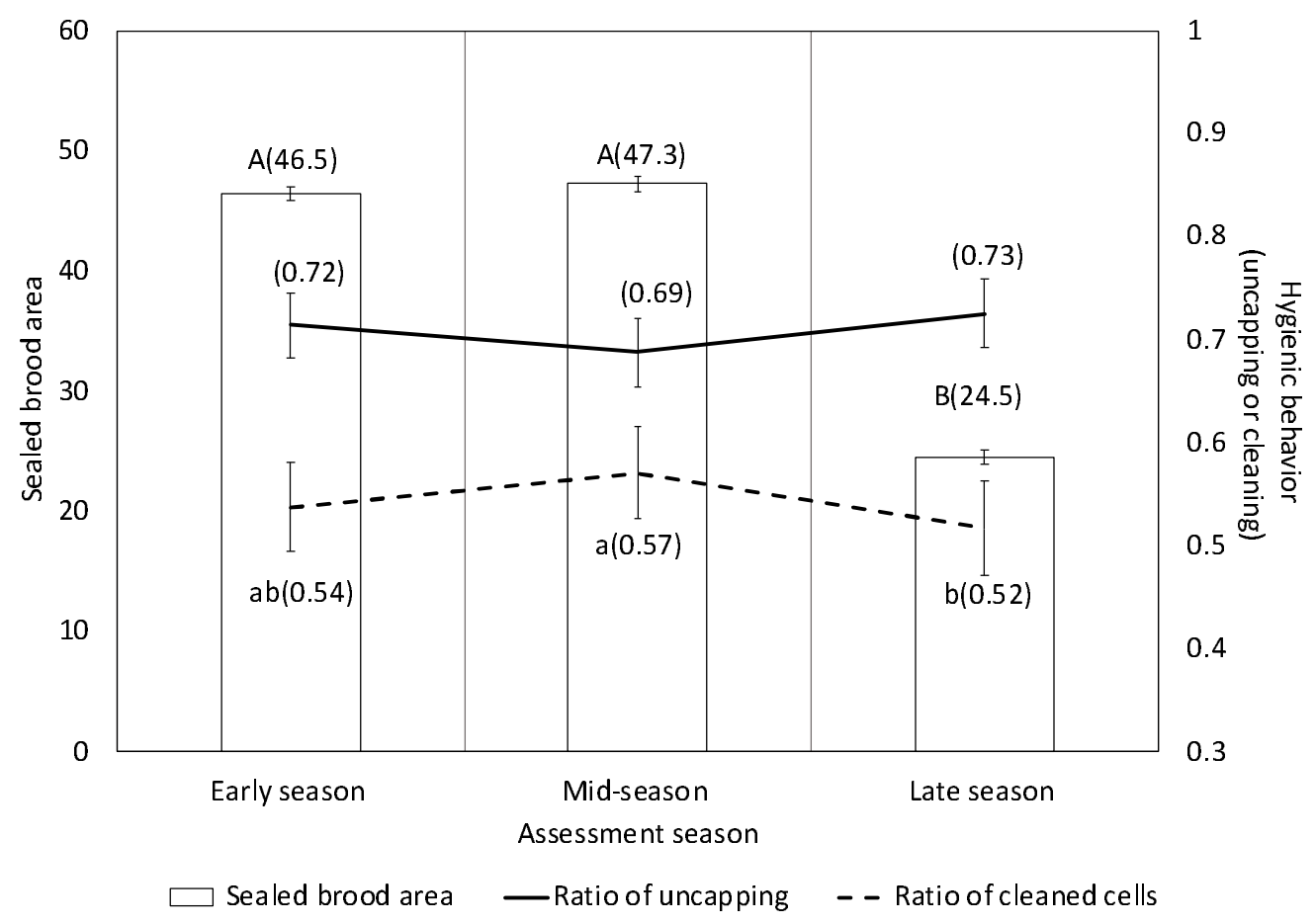

247 Fig. 2: Seasonal changes in sealed brood area and in rate of hygienic behavior. The bars represent

248 sealed brood area (average $\pm \mathrm{SE}$ ) and lines represent hygienic behavior: proportion of uncapping 249 (solid line) or cleaning (dashed line) at different times of the year. The values of average rate of 250 seasonal performances are presented in parentheses. The $\mathrm{x}$-axis represents time of assessment 251 relative to the honeybee season: early season, mid-season, and late season. Significant 252 differences between the seasonal measurements (population size and hygienic behavior) are 253 labeled by different letters (post-hoc Tukey's HSD, $p<0.05$ ). The average seasonal performance is 254 presented in parentheses.

The selection according to the maternal phenotype was successful (Table 2).

257 Throughout the duration of the research, the high hygienic progeny colonies had 258 significantly higher levels of both uncapping and cleaning behaviors compared to the 
259 low hygienic progeny colonies (high and low respectively, for uncapping $0.8 \pm 0.01 \mathrm{vs}$.

$260 \quad 0.6 \pm 0.01$ (mean \pm SE) $p<0.0001$, and for cleaning $0.6 \pm 0.03$ and $0.4 \pm 0.03$ (mean \pm SE)

\section{Response}

$261 p=<0.0001)$. The maternal mating type had a significant effect on the cleaning

262 behavior, but not on the uncapping behavior (Table 2). In progeny that were tested for

263 two generations, there was a significant interaction between the maternal phenotype

264 and mating type for both uncapping and cleaning (Table 2), accentuating the

265 differences between the high and low selection lines. Progeny of high hygienic queens

266 that were artificially inseminated had average uncapping behavior of $0.75 \pm 0.04$ and

267 average cleaning behavior of $0.59 \pm 0.04$. By comparison, progeny of low hygienic

268 queens that were artificially inseminated had an average uncapping behavior of

$2690.4 \pm 0.03$ and average cleaning behavior of $0.26 \pm 0.04$. On the other hand, for the

270 progeny of the naturally-mated queens, the difference between the two phenotypes

271 were more moderate. Progeny of the naturally-mated high hygienic queens had an

272 average of uncapping and cleaning behaviors of $0.77 \pm 0.04$ of $0.62 \pm 0.02$, respectively.

273 Progeny of naturally-mated low hygienic queens seem to have lost their low parental

274 phenotype and showed an average of $0.70 \pm 0.03$ and $0.55 \pm 0.02$ uncapping and

275 cleaning behaviors, respectively. Regarding the random variables, colony identity

276 was the only parameter that was significant in our model (uncapping: $F_{(261,477)}=2.66$,

$277 \quad p<0.0001$ and cleaning: $\mathrm{F}_{(261,477)}=2.2, p<0.0001($ Table 2$\left.)\right)$. 


\begin{tabular}{|c|c|c|}
\hline Variables & $\begin{array}{c}\text { Proportion of uncapped } \\
\text { cells }\end{array}$ & $\begin{array}{c}\text { Proportion of cleaned } \\
\text { cells }\end{array}$ \\
\hline Maternal phenotype & $\mathrm{F}_{(1,7)}=35$, & $\mathrm{F}_{(1,7)}=36$, \\
$p<0.0001^{*}$ & $\mathrm{~F}_{(1,16)}=5$, \\
& $\mathrm{F}_{(1,7)}=35$, & $p=0.02^{*}$ \\
\hline Maternal mating type & $p=0.95$ & $\mathrm{~F}_{(1,7)}=8.8$, \\
& $\mathrm{F}_{(1,7)}=5.8$, \\
$p<0.0001^{*}$ & $p=0.003^{*}$ \\
\hline Maternal phenotype x Maternal mating & $\mathrm{F}_{(261,477)}=2.66$, & $\mathrm{F}_{(261,477)}=2.2$, \\
type & $p=0.0001^{*}$ & $p<0.0001^{*}$ \\
\hline Colony (Random) & $\mathrm{F}_{(3,14)}=1.37$, & $\mathrm{F}_{(3,17)}=2.18$, \\
& $p=0.29$ & $p=0.12$ \\
\hline Year (Random) & &
\end{tabular}

Table 2: The effect of maternal phenotype (high or low hygienic behavior), maternal mating type (naturally-mated or artificially inseminated), and the interaction among them on hygienic parameters (cell uncapping and cell cleaning). Significant differences in two-way ANOVA among tested groups are marked by an asterisk (colony identity and the year of measurement were taken into consideration in our model as random effects).

287 Maternal phenotype had a significant effect on parasite load $\left(\mathrm{F}_{(1,120)}=123, \quad p=\right.$

288 0.0007). We found the value of this variable to be significantly lower in high hygienic

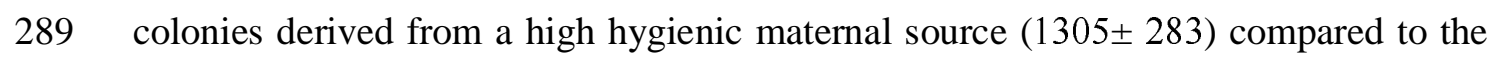

290 low hygienic colonies $(2858 \pm 275)$. The year of testing had also a significant effect

291 on Varroa infestation $\left(\mathrm{F}_{(, 3,120)}=23.4, p<0.0001\right)$. The extreme fluctuation in Varroa

292 infestation was exemplified between the years 2016 and 2015. In 2016, we had the

293 lowest Varroa infestation, with an average of $477 \pm 333$ per colony. Conversely, the

294 maximum infestation was measured in 2015, with an average of $5005 \pm 453$. 


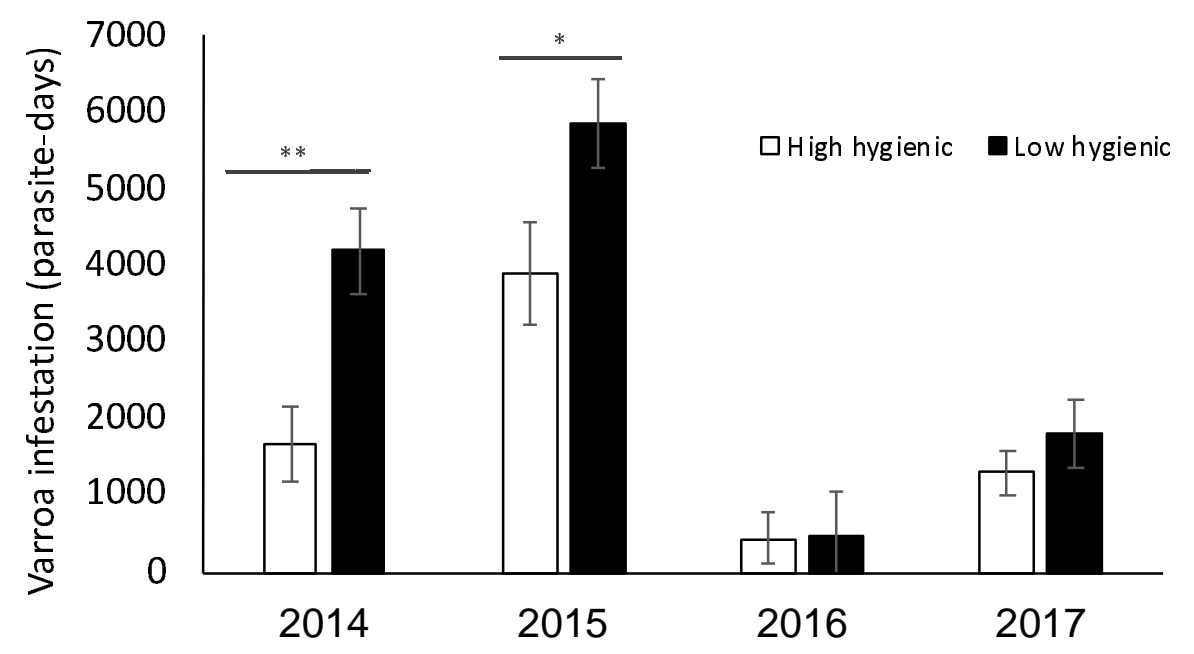

297 infestation, maternal phenotype had a significant effect (in 2014, $\mathrm{F}_{(1,120)}=11.4, \quad p=$

2980.001 and in 2015, $\mathrm{F}_{(1,120)}=4.6, \quad p=0.033$, Fig. 3). Obviously in years with low 299 Varroa infestation, the secondary effect of maternal phenotype did not have a 300 significant Impact on the parasite load (in 2016, $\mathrm{F}_{(1,120)}=0.0031, \quad p=0.95$ and in $3012017, \mathrm{~F}_{(1,120)}=0.9, p=0.34$, Fig. 3).

302 Fig 3: Differences in Varroa infestation between high and low hygienic maternal lines during four 303 years of testing. Varroa infestation is presented in high hygienic (white bar) and low hygienic 304 (black bar) progeny. The data are: average \pm SE. The asterisks indicate significant differences in 305 Varroa load between the two groups (post-hoc Tukey's HSD, $p<0.05$ ).

Honey production: A two-way ANOVA analysis of honey yield was 308 performed in order to determine the benefits and identify possible tradeoffs of the 309 selected lines. No significant effect of maternal phenotype was found on honey yields 310 in both seasons (Table 3). In particularly, spring honey yields averaged \pm SE: 21.3 $311 \pm 3.6 \mathrm{~kg}$ for high hygienic maternal lines and $21.5 \pm 3.6 \mathrm{~kg}$ for low hygienic lines; 312 summer honey yields averaged: $14.4 \pm 2.3 \mathrm{~kg}$ for high hygienic maternal lines and 
$31313.8 \pm 2.3 \mathrm{~kg}$ for low hygienic lines. Annual honey yields averaged $35.2 \pm 3.5 \mathrm{~kg}$ for

314 high hygienic maternal lines and $34.6 \pm 3.5 \mathrm{~kg}$ for low hygienic lines. Maternal mating

315 type also had no significant effect on honey yields in both seasons (Table 3). For

316 spring honey yields, artificially inseminated queens' progeny had on average, $22 \pm 3.8$

$317 \mathrm{~kg}$ while progeny of naturally mated queens had on average $20.8 \pm 3.5 \mathrm{~kg}$. For summer

318 honey yields, artificially inseminated queens' progeny had $13.8 \pm 2.8 \mathrm{~kg}$ while progeny

319 of naturally mated queens had $14.4 \pm 2 \mathrm{~kg}$ (Table 3). For annual honey yields

320 artificially inseminated queens' progeny had on average $35.5 \pm 4 \mathrm{~kg}$ and naturally

321 mated queens' progeny had $34.3 \pm 3 \mathrm{~kg}\left(\mathrm{~F}_{(1,11)}=0.2, p=0.8\right.$ (Table 3$)$. We found that the

322 year of testing (taken into consideration as a random effect) had a significant effect on

323 honey yield. This is a well-known phenomenon which is mainly explained by the

324 differences in environmental conditions between years.

325 Table 3: The effects of maternal phenotype type (high or low hygienic behavior) and maternal 326 mating type (naturally-mated or artificially inseminated), and their interaction on honey yields.

327 Significant differences in two-way ANOVA between tested groups are marked with an asterisk.

328 The years of measurement were considered as random effects.

329

331 between them did not have a significant effect on honey yield or on the sealed brood

332 area (Tables 2 and 3). A very low but nonetheless significant negative correlation

333 between uncapping and spring honey yields, was found (Fig. 4A: Pearson, $r=-0.137$, 
$334 p=0.0093$ ), but practically no correlation regarding cell cleaning (Fig 4B: $\mathrm{r}=-0.09, p$

$335=0.07)$. In contrast, there was a low but positive and significant correlation between

336 summer yields and both measurements of hygienic behavior (Fig. 4C: $r=0.172, p$

$337=0.003$; and Fig. 4D: $\mathrm{r}=0.147 p=0.0061)$. Overall, there was no correlation between

338 the annual yield (sum of spring and summer yields) and hygienic behavior (Fig 4E: $r$

$339=-0.014 p=0.78$ and Fig. 4F: $\mathrm{r}=0.008 p=0.87)$. Taking all of this into consideration,

340 we believe that the correlation was significant, mainly due to a large sample size. This

341 is evident in the pattern of scattered points around the line.
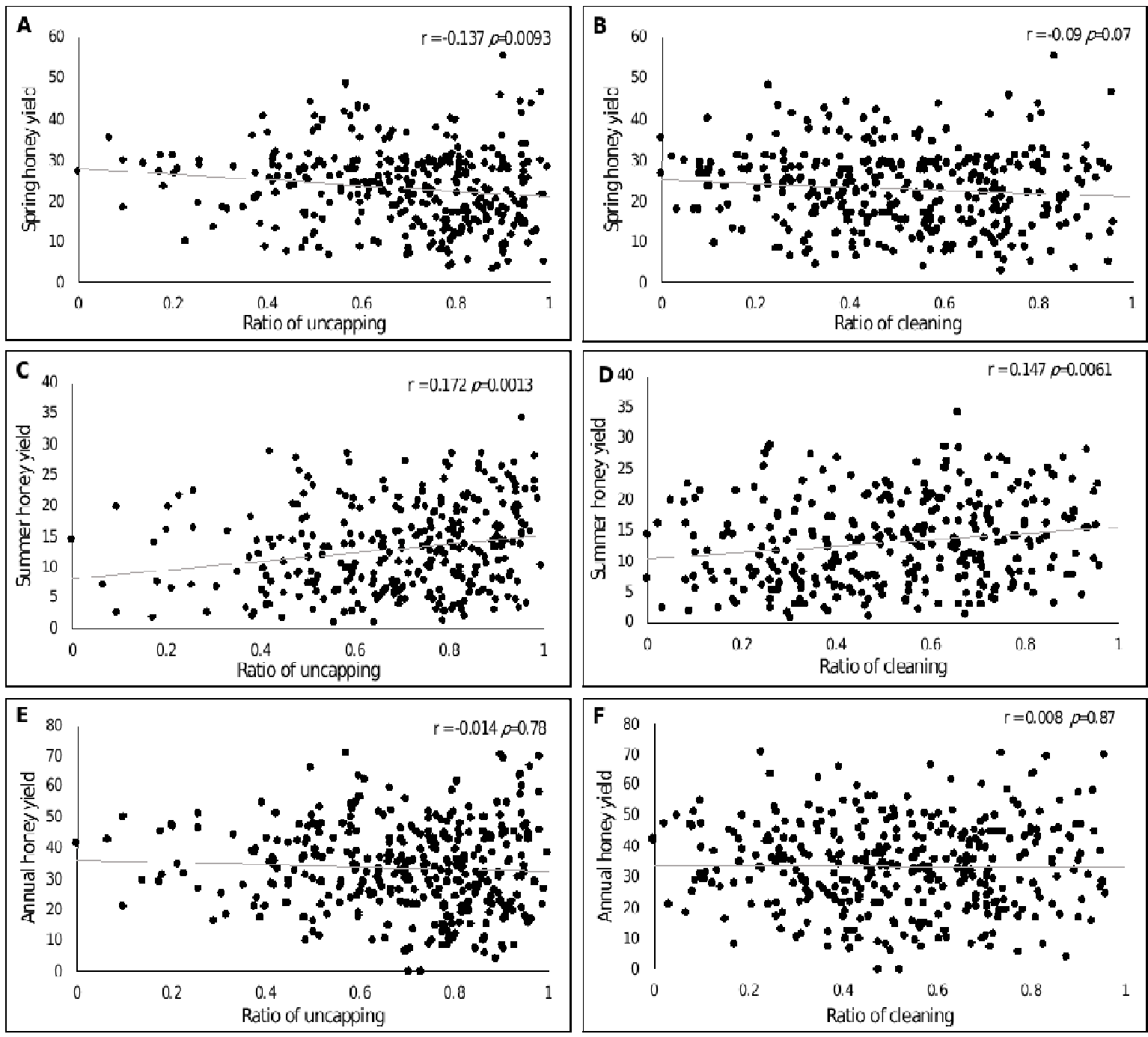

Fig 4: Correlations between uncapping and cleaning of pin damaged brood and colony honey

344 production. Each point represents a different colony. Axis X represents rate of hygienic behavior

345 (proportion of uncapped or cleaned brood cells) and the $\mathrm{Y}$ axis represents honey yield in $\mathrm{kg}$. 
346 Spring honey yields (A and B), Summer honey yields (C and D) and Annual honey yields (E and

347 F) are shown in the figures. The Pearson correlation is represented by $\mathrm{r}$ and $p$ values.

\section{Discussion}

Advanced and sustainable management of Varroa infestation must include the

350 selection of honeybee lines that show some degree of resistance to the parasite. Here,

351 we evaluated the feasibility of breeding for hygienic behavior as part of Varroa

352 management strategy. Our breeding program is unique in that it was carried out in a

353 Mediterranean climate, where colony loss occurs primarily in the summer as opposed

354 to colder regions, where it is most common in winter (Doke et al. 2015). It is well

355 known that there is huge variability in climatic zones and diverse habitats in which

356 honey bees are found. Therefore, we based our hygienic selection on bees that were

357 already adapted to local environmental conditions. This approach supports the

358 preservation of locally-adapted honey bees (Costa et al. 2012; Uzunov et al. 2014).

359 First, we examined the characteristics of hygienic behavior in our study population,

360 namely uncapping and cleaning. As expected, in our study, these hygienic associated

361 behaviors were strongly correlated. Although it is clear that cleaning behavior

362 depends on uncapping, the two together are a prerequisite for successful pest and

363 pathogen control including Varroa (Spivak and Danka 2021). Next, we analyzed

364 seasonal effects on hygienic behavior. Seasonality is linked to environmental changes

365 (e.g., temperature, humidity and precipitation), and thus leads to dramatic fluctuations

366 in honey bee population size. The sealed brood area is an indicator of population size,

367 and as a result, it also represents the number of bees at the age of performing hygienic

368 behavior. Some previous studies have suggested an association between the rate of

369 hygienic behavior and seasonal fluctuation in colony size (Uzunov et al. 2014), as

370 well as environmental factors that affect hygienic behavior (Güler and Toy 2013). In 
371 contrast, both our results and those of Bigio et al. (2013) demonstrate that hygienic

372 behavior is rather stable along the season and is independent of the population size.

373 We found that in our conditions hygienic behavior is rather stable along the season

374 and fluctuates very little in comparison to the dramatic fluctuations of population size 375 between the seasons.

376 In agreement with previous research (e.g., Spivak and Reuter 1998; Fly et al.

377 2014; Zakour and Bienefeld 2014; Danka et al. 2016; de Jesus et al. 2017;

378 Scannapieco et al. 2017), we have found that maternal colony phenotype has a 379 significant effect on hygienic behavior, which emphasizes the potential of breeding 380 for this trait in the local population. We also found a significant interaction between 381 maternal phenotype and mating technique, indicating that artificially inseminated 382 daughters preserve the maternal phenotype better than daughters of naturally-mated 383 daughter queens. This contradicts Bigio et al. (2014a), who claim that there are no 384 advantages in using artificially inseminated queens while breeding for hygienic 385 behavior. Our results indicate that selection based solely on queens is not enough. In 386 fact, the model published by Plate et al. (2019) that simulated the power of selection 387 in a drone controlled set-up, clearly shows that the selection based solely on queens in 388 a large non-selected population is insufficient.

389 Although pin-killed assays for hygienic behavior is not specific to Varroa 390 infected brood (Spivak and Danka 2021) and it is preferable to test such resistance 391 directly by challenging colonies with a parasite, our results clearly showed that lines 392 derived from a high hygienic maternal source, based on pin killed brood assay, also 393 demonstrated a lower parasite load when compared to low hygienic progeny colonies. 394 Moreover, lower loads of Varroa mites could result in lower virus infestation (Locke 395 2012; Kuster et al. 2014; Mondet et al. 2014), which most likely leads to lower virus 
396 transmission and improved colony health. Nevertheless, this notion has been 397 questioned by Geffre et al. (2020) as viruses can alter honeybee social behavior. Since 398 this behavior increases contact between the workers and infected brood, the 399 implication of hygienic behavior on viral transmission within and between the 400 colonies as well as the association between Varroa infestation, viral load, and social 401 and individual immunity remain to be thoroughly investigated.

402 Lastly, the feasibility of implementation of honey bees' hygienic lines in a 403 commercial apiary is tightly linked to the apicultural costs maintaining such lines and 404 whether selection for hygienic trait compromises other desired traits. Seeley (1985) 405 raised a concern about a high cost for hygienic behavior due to the inadvertent 406 removal of healthy brood from the colony. In fact, in our study we found that progeny 407 of low hygienic colonies had more sealed brood, but this could suggest that colonies 408 kept the unhealthy brood rather than the hygienic colonies unintentionally removed 409 the healthy brood. Unfortunately, in our experiments we have not compared the brood 410 quality between the genotypes to test this hypothesis and it should be tested in the 411 future studies. Anyhow, several studies have already shown that hygienic behavior is 412 specifically directed towards damaged brood (Bigio et al. 2014b; Mondet et al. 2016). 413 Potential payoffs and tradeoffs of hygienic behavior with respect to honey yield, 414 propolis production, royal jelly, aggressive behavior, and swarming tendency were 415 reviewed in Leclercq et al. (2017). They concluded that there were no major tradeoffs 416 associated with hygienic behavior. Yet every local breeding program should test the 417 payoffs and tradeoffs of their selected lines, since the latter could carry undesired 418 additional traits. Our analyses of selected lines revealed no impact on annual honey 419 yield or population size except for a small significant negative correlation with 420 uncapping behavior and spring honey yield. There may, however, be a benefit to the 
421 trait, supported by the positive correlation between summer honey yield and hygienic

422 performance. The advantage of high hygienic lines was reflected in the strength of the

423 colony during the summer peak of Varroa infestation. We hypothesize that this trend

424 would be of great importance due to the ever-growing abundance of acaricide

425 resistant mites in intensive commercial beekeeping.

426 In conclusion, our results show that not only the hygienic trait exists in a local 427 population bred for years for honey production, but that selection for this trait reduced 428 Varroa infestation without negative impacts on colony size and honey production.

429 Therefore, it is safe to recommend its introduction into local breeding programs as a 430 basis for future integrated Varroa management. Moreover, since the literature 431 demonstrates that hygienic behavior is efficient against several bee diseases, such as 432 American foulbrood and chalkbrood (Spivak and Reuter 2001; Leclercq et al. 2017), 433 it will be interesting to test the impact of our selection program on the management of 434 these two diseases in a Mediterranean climate, as well as on the spread of other bee 435 viral diseases.

\section{Authors' Contribution}

437 RS, AHefetz and VS designed the experiments. RS, PK, YK, and VS performed the 438 experiments. MB performed and instructed the process of artificial insemination. A 439 Hetzroni constructed the database, and RS analyzed the data. RS, MB, AHefetz and 440 VS wrote the manuscript. All authors agreed to the final version of publication and its 441 content. 


\section{Acknowledgments}

443 We wish to thank the beekeeper Ilia Zaidman for technical assistance with colonies,

444 Dr. Hillary Voet for her help with statistical analysis, Dr. Beatrice Nganso for her

445 critical review on the draft of this manuscript and BARD Binational Foundation grant

446 IS-5078-18 to VS for funding final stages of this research.

\section{References}

448

449

450

451

452

453

454

455

456

457

458

459

460

461

462

463

464

465

466

467

468

469

470

471

472

473

474

475

476

477

478

479

480

481

482

483
Arathi HS, Spivak M (2001) Influence of colony genotypic composition on the performance of hygienic behaviour in the honeybee, L. Anim Behav 62:57-66. doi: 10.1006/anbe.2000.1731

Bigio G, Al Toufailia H, Hughes WOH, Ratnieks FLW (2014a) The effect of one generation of controlled mating on the expression of hygienic behaviour in honey bees. J Apic Res 53:563-568. doi: 10.3896/IBRA.1.53.5.07

Bigio G, Al Toufailia H, Ratnieks FLW (2014b) Honey bee hygienic behaviour does not incur a cost via removal of healthy brood. J Evol Biol 27:226-230. doi: $10.1111 /$ jeb. 12288

Bigio G, Schürch R, Ratnieks FLW (2013) Hygienic Behavior in Honey Bees (Hymenoptera: Apidae): Effects of Brood, Food, and Time of the Year. J Econ Entomol 106:2280-2285

Boecking O, Bienefeld K, Dreschner W (2000) Heritability of the Varroa-specific hygienic behaviour in honey bees (Hymenoptera: Apidae). J Anim Breed Genet 117:417-424. doi: 10.1046/j.1439-0388.2000.00271.x

Büchler R, Andonov S, Bienefeld K, et al (2013) Standard methods for rearing and selection of Apis mellifera queens. J Apic Res 52:1-30. doi: 10.3896/IBRA.1.52.1.07

Büchler R, Berg S, Le Conte Y, et al (2010) Breeding for resistance to Varroa destructor in Europe. Apidologie 41:393-408. doi: 10.1051/apido/2010011

Büchler R, Costa C, Hatjina F, et al (2014) The influence of genetic origin and its interaction with environmental effects on the survival of Apis mellifera $\mathrm{L}$. colonies in Europ. J Apic Res 53:205-214. doi: 10.3896/IBRA.1.53.2.03

Costa C, Büchler R, Berg S, et al (2012) A europe-wide experiment for assessing the impact of genotype-environment interactions on the vitality and performance of honey bee colonies: experimental design and trait evaluation. J Apic Sci 56:147158. doi: 10.2478/v10289-012-0015-9

Danka RG, Harris JW, Dodds GE (2016) Selection of VSH-derived "Pol-line" honey bees and evaluation of their Varroa-resistance characteristics. Apidologie 47:483-490. doi: 10.1007/s13592-015-0413-7

de Jesus JN, Chambó ED, da Silva Sodré G, et al (2017) Hygienic behavior in Melipona quadrifasciata anthidioides (Apidae, Meliponini). Apidologie 48:504512. doi: 10.1007/s13592-017-0495-5

Delaplane and Mayer (2000) Crop pollination by bees. Design 99:127-129. doi: 10.1046/j.1570-7458.2001.00810.x

Dietemann V, Nazzi F, Martin SJ, et al (2013) Standard methods for varroa research. 
J Apic Res 52:. doi: 10.3896/IBRA.1.52.1.09

Dietemann V, Pflugfelder J, Anderson D, et al (2012) Varroa destructor: research avenues towards sustainable control. J Apic Res 51:125-132. doi: 10.3896/IBRA.1.51.1.15

Doke MA, Frazier M, Grozinger CM (2015) Overwintering honey bees: biology and management. Curr Opin Insect Sci 10:185-193. doi: 10.1016/j.cois.2015.05.014

Dolezal AG, Carrillo-Tripp J, Miller WA, et al (2016) Intensively cultivated landscape and varroa mite infestation are associated with reduced honey bee nutritional state. PLoS One 11:1-13. doi: 10.1371/journal.pone.0153531

Evans JD, Spivak M (2010) Socialized medicine: Individual and communal disease barriers in honey bees. J Invertebr Pathol 103:S62-S72. doi: 10.1016/j.jip.2009.06.019

Fly MF, Capitata C, Khlaywi SA, et al (2014) Hygienic behavioural mechanism of resistance to diseases and parasites in west african honey bee colonies Apis mellifera adansonii (Hymenoptera: apidae) aakinwande. Int J Entomol Res 02:169-173

Francis RM, Nielsen SL, Kryger P (2013) Varroa-Virus Interaction in Collapsing Honey Bee Colonies. PLoS One 8:. doi: 10.1371/journal.pone.0057540

Geffre AC, Gernat T, Harwood GP, et al (2020) Honey bee virus causes contextdependent changes in host social behavior. Proc Natl Acad Sci 117:1-8. doi: 10.1073/pnas.2002268117

Gempe T, Stach S, Bienefeld K, et al (2016) Behavioral and molecular studies of quantitative differences in hygienic behavior in honeybees. BMC Res Notes 1-8. doi: 10.1186/s13104-016-2269-y

Genersch E, Von Der Ohe W, Kaatz H, et al (2010) The German bee monitoring project: A long term study to understand periodically high winter losses of honey bee colonies. Apidologie 41:332-352. doi: 10.1051/apido/2010014

Gregory PG, Evans JD, Rinderer T, de Guzman L (2005) Conditional immune-gene suppression of honeybees parasitized by varroa mites. J Insect Sci 5:1-5. doi: 10.1673/031.005.0701

Guarna M, Melathopoulos AP, Huxter E, et al (2015) A search for protein biomarkers links olfactory signal transduction to social immunity. BMC Genomics 16:63. doi: 10.1186/s12864-014-1193-6

Güler A, Toy H (2013) Relationship between dead pupa removal and season and productivity of honey bee (Apis mellifera, Hymenoptera: Apidae) colonies. Turkish J Vet Anim Sci 37:462-467. doi: 10.3906/vet-1205-48

Klein A-M, Vaissiere BE, Cane JH, et al (2007) Importance of pollinators in changing landscapes for world crops. Proc R Soc B Biol Sci 274:303-313. doi: 10.1098/rspb.2006.3721

Kuster RD, Boncristiani HF, Rueppell O (2014) Immunogene and viral transcript dynamics during parasitic Varroa destructor mite infection of developing honey bee (Apis mellifera) pupae. J Exp Biol 217:1710-1718. doi: 10.1242/jeb.097766

Le Conte Y, Alaux C, Martin JF, et al (2011) Social immunity in honeybees (Apis mellifera): Transcriptome analysis of varroa-hygienic behaviour. Insect Mol Biol 20:399-408. doi: 10.1111/j.1365-2583.2011.01074.x

Le Conte Y, Meixner MD, Branndt A., et al (2020) Geographical distribution and selection of European honey bees resistant to Varroa destructor. Insects, 11 doi: 10.3390/insects11120873

Leclercq G, Pannebakker B, Gengler N, et al (2017) Drawbacks and benefits of hygienic behavior in honey bees (Apis mellifera L.): a review. J. Apic. Res. 
552

553

554

555

556

557

558

559

560

561

562

563

564

565

566

567

568

569

570

571

572

573

574

575

576

577

578

579

580

581

582

583 56:366-375

Locke B (2016) Natural varroa mite-surviving Apis mellifera honeybee populations. Apidologie 47:467-482. doi: 10.1007/s13592-015-0412-8

Locke B (2012) Host-parasite adaptations and interactions between honey bees, varroa mites and viruses

Meixner MD, Büchler R, Costa C, et al (2014) Honey bee genotypes and the environment. J Apic Res 53:183-187. doi: 10.3896/IBRA.1.53.2.01

Mondet F, de Miranda JR, Kretzschmar A, et al (2014) On the front line: quantitative virus dynamics in honeybee (Apis mellifera L.) colonies along a new expansion front of the parasite Varroa destructor. PLoS Pathog 10:e1004323. doi: 10.1371/journal.ppat.1004323

Mondet F, Kim SH, de Miranda JR, et al (2016) Specific cues associated with honey bee social defence against Varroa destructor infested brood. Sci Rep 6:25444. doi: 10.1038/srep25444

Mullin CA, Frazier M, Frazier JL, et al (2010) High levels of miticides and Agrochemicals in North American Apiaries: Implications for Honey Bee Health. PLoS One 5:e9754. doi: 10.1371/journal.pone.0009754

Niño EL, Cameron Jasper W (2015) Improving the future of honey bee breeding programs by employing recent scientific advances. Curr Opin Insect Sci 10:163169. doi: 10.1016/j.cois.2015.05.005

Oxley PR, Oldroyd BP (2010) The genetic architecture of honeybee breeding. Advances in Insect Physiology 39:83-118. DOI: 10.1016/B978-0-12-3813879.00003-8

Plate M, Bernstein R, Hoppe A, Bienefeld K (2019) The importance of controlled mating in honeybee breeding. Genet Sel Evol 51:74. doi: 10.1186/s12711-0190518-y

Plettner E, Eliash N, Singh NK, et al (2016) The chemical ecology of host-parasite interaction as a target of Varroa destructor control agents. Apidologie 48:78-92. doi: 10.1007/s13592-016-0452-8

Ramsey SD, Ochoa R, Bauchan G, et al (2019) Varroa destructor feeds primarily on honey bee fat body tissue and not hemolymph. Proc Natl Acad Sci U S A 116:1792-1801. doi: 10.1073/pnas.1818371116

Rosenkranz P, Aumeier P, Ziegelmann B (2010) Biology and control of Varroa destructor. J Invertebr Pathol 103:S96-S119. doi: 10.1016/j.jip.2009.07.016

Ryabov E V., Wood GR, Fannon JM, et al (2014) A Virulent Strain of Deformed Wing Virus (DWV) of Honeybees (Apis mellifera) Prevails after Varroa destructor-mediated, or in vitro, transmission. PLoS Pathog 10:e1004230. doi: 10.1371/journal.ppat.1004230

Sammataro D, Avitabile A (2011) The beekeeper's handbook, 4th ed. Comstock Pub. Associates, Ithaca

Sammataro D, Untalan P, Guerrero F, Finley J (2005) The resistance of varroa mites (Acari: Varroidae) to acaricides and the presence of esterase. Int J Acarol 31:6774. doi: 10.1080/01647950508684419

Scannapieco AC, Mannino MC, Soto G, et al (2017) Expression analysis of genes putatively associated with hygienic behavior in selected stocks of Apis mellifera L. from Argentina. Insectes Soc 64:485-494. doi: 10.1007/s00040-017-0567-6

Seeley TD (1985) Honeybee Ecology. Princeton University Press, Princeton, New Jersey

Simon-Delso N, Martin GS, Bruneau E, et al (2014) Honeybee Colony Disorder in 
584

585

586

587

588

589

590

591

592

593

594

595

596

597

598

599

600

601

602

603

604

605

606

607

608

609

610

611

612

613

614

615

616

617

618

619

620

621

622

623

624

625

626

627

628

629

630

631

632
Crop Areas: The Role of Pesticides and Viruses. PLoS One 9:e103073. doi: 10.1371/journal.pone.0103073

Soroker V, Slobezki Y, Chejanovsky N (2018) Apiculture in Israel. Asian Beekeeping in 21st Century 95-109. doi: 10.1007/978-981-10-8222-1_4

Soroker V, Singh, KN, Eliash, N, Plettner, E. (2019) Olfaction as a target for control of honeybee parasitic mite Varroa destructor. Ch. 6 in: Olfactory concepts of pest control. J-F. Picimbon ed. Springer (2019).

Spivak M, Danka RG (2021) Perspectives on hygienic behavior in Apis mellifera and other social insects. Apidologie 52:1-16. doi: 10.1007/s13592-020-00784-z

Spivak M, Gilliam M (1998) Hygienic behaviour of honey bees and its application for control of brood diseases and varroa. Bee World 79:169-186. doi: 10.1080/0005772X.1998.11099394

Spivak M, R.Euter GS (2001) Resistance to American foulbrood disease by honey bee colonies Apis mellifera bred for hygienic behavior. Apidologie 32:555-565. doi: 10.1051/apido:2001103

Spivak M, Reuter GS (1998) Performance of hygienic honey bee colonies in a commercial apiary. Apidologie 29:291-302. doi: 10.1051/apido

Steinhauer, N, Kulhanek K., K, Antúnez, et al (2018) Drivers of colony losses, Current Opinion in Insect Science26: 142-148, /doi:10.1016/j.cois.2018.02.004.Thomas E. Rinderer, Lilia I. de Guzman, G.T. Delatte, et al (2001) Resistance to the parasitic mite Varroa destructor in honey bees from far-eastern Russia. Apidologie 32:381-394. doi: 10.1051/apido:2001138

Uzunov A, Brascamp EW, Büchler R (2017) The basic concept of honey bee breeding programs. Bee World 94:84-87. doi: 10.1080/0005772x.2017.1345427

Uzunov A, Cost C, Panasiuk B, et al (2014) Swarming, defensive and hygienic behaviour in honey bee colonies of different genetic origin in a pan-European experiment. J Apic Res 53:248-260. doi: 10.3896/IBRA.1.53.2.06

VanEngelsdorp D, Meixner MD (2010) A historical review of managed honey bee populations in Europe and the United States and the factors that may affect them. J Invertebr Pathol 103:S80-S95. doi: 10.1016/j.jip.2009.06.011

Yang X, Cox-Foster DL (2005) Impact of an ectoparasite on the immunity and pathology of an invertebrate: evidence for host immunosuppression and viral amplification. Proc Natl Acad Sci U S A 102:7470-7475. doi: 10.1073/pnas.0501860102

Zakar E, Javor A, Kusza S (2014) Genetic bases of tolerance to Varroa destructor in honey bees (Apis mellifera L.). Insectes Soc 61:207-215. doi: 10.1007/s00040014-0347-5

Zakour MK, Bienefeld K (2014) Basic considerations in the development of breeding plans for honey bees, illustrated by data on the native Syrian honey bee (Apis mellifera syriaca). doi: 10.3896/IBRA.1.53.2.13

Zanni V, Galbraith DA, Annoscia D, et al (2017) Transcriptional signatures of parasitization and markers of colony decline in Varroa-infested honey bees (Apis mellifera). Insect Biochem Mol Biol 87:1-13. doi: 10.1016/j.ibmb.2017.06.002

Zioni N, Soroker V, Chejanovsky N (2011) Replication of Varroa destructor virus 1 (VDV-1) and a Varroa destructor virus 1-deformed wing virus recombinant (VDV-1-DWV) in the head of the honey bee. Virology 417:106-112. doi: 10.1016/j.virol.2011.05.009 